“Immigration and the Life Course," special issue, Canadian Studies in Population 40, no. 1-2 (Spring/Summer 2013): 1-8.

\title{
Lifecourse perspectives on immigration
}

\author{
Barry Edmonston \\ Department of Sociology and Population Research Group, University of Victoria \\ be@uvic.ca
}

\section{Background}

The lifecourse perspective examines individual life histories in order to understand how prior events, social and economic conditions, and individual characteristics influence decisions and events over time. The lifecourse approach emphasizes the connection between individuals and the historical context in which their lives take place. This approach has its origins in Thomas and Znaniecki's pioneering studies (1918-1920) of the migration and adaptation of Polish peasants in Europe and the United States (Thomas and Znaniecki 1958). Their work examined how the lives of Polish peasants changed over time within social, economic, and cultural contexts. In recent years, the lifecourse perspective has been used to study how events earlier in life—such as schooling or teenage experiences—affect later decisions and events, such as childbearing, marriage and divorce, and retirement.

In early studies in the 1930s and 1940s, longitudinal studies of individuals followed children or adults only for a few years. Generally, this early work was interested in the sequence of social roles, such as childhood socialization, becoming married, or transition to parenthood - a process that demographers called life cycle studies or the study of key transitions in individual lives. Studies dealing with the life cycle were particularly prominent in family demography (Glick 1988), as evidenced by the large number of publications dealing with family trends, religious and racial intermarriage, social-economic changes and family stability, changes in age at first marriage, and the prevalence of divorce in the 1950s and 1960s. Recent studies in family demography demonstrate the continued usefulness of the life cycle for studying such topics as cohabitation outside marriage, one-parent families, gender preferences in children, nofault divorce, divorce among children of divorce, and stepfamilies.

Other researchers, notably at the University of California, Berkeley's Institute of Human Development in the 1950s, realized that the study of single individuals oversimplified the lives of people, who were interacting with others and were entrenched in a broader historical context. As longitudinal studies developed—in ways discussed belowlife cycle theory was expanded to what is now called lifecourse perspective.

Although the early use of a lifecourse perspective dealt with migration, very few recent studies of migration have explicitly employed a lifecourse approach. In June 2010, the Committee on Migration and Immigration of the Population Change and Lifecourse Strategic Knowledge Cluster ${ }^{1}$ organized a workshop at the University of Montreal to explore the value of a lifecourse perspective on immigration. This workshop included ten papers that dealt with a variety of immigration topics. Six papers from that workshop have been revised for publication in this special issue of Canadian Studies in Population.

\section{Central questions for migration analysis}

Migration has several unique features. First, migration does not occur in a vacuum. When a migrant moves, it affects persons in the community of origin as well as the community of destination. Likewise, migration is influenced greatly by social and economic conditions in the communities of origin and destination.

Secondly, migration is rooted in time. Migration is located in a particular historical period and reflects the influence of social and economic conditions in that period. Migration takes place at different ages and has an effect on a person over their lifetime. Possible future migration can also affect current behaviour, because a person thinking that they may one day migrate will make different decisions than someone who does not intend to migrate.

Jasso (2003: 334) notes that the study of migration poses four central questions.

1. http://sociology.uwo.ca/cluster/en/. 
1. Migrants at the time of entry: Many studies deal with the characteristics of immigrants at the time of arrival, usually examining differences by age, sex, or country of origin. One important type of study involves changes in selectivity over time, attempting to understand whether there have been declines or improvements in immigrant characteristics across immigrant arrival cohorts. If, for instance, successive immigrant cohorts have declining educational levels, than this would influence labour force participation, occupational choices, and individual income, as well as other measures of immigrant adaptation.

2. The progress of migrants after migration: A critical policy-related question deals with the relative success (or failure) of immigrants after arrival in their new destination community. Not all immigrants stay after immigration, and some return to their home country or emigrate to a third country (which is an important issue). For those immigrants who remain, numerous studies deal with topics variously referred to as assimilation, acculturation, adaptation, and integration of immigrants. These studies comprise the bulk of recent immigration research in Canada and other immigrant-receiving countries.

3. The progress of migrant children and the children of migrants: The third central question deals with the issue of migrants who arrive as children (who differ from adult immigrants because they experience early childhood and schooling in their new community) or are the children of immigrants. The initial characteristics of children are different than migrants who arrive as adults, and they progress differently over time. The relative success of the 2nd immigrant generation — the sons and daughters of immigrants—is an important topic for study because it has implications for the long-term incorporation of immigrants from different origins.

4. The effects of migration: Migration affects two communities, one at place of origin and another at the place of destination. Studies of the loss of skilled migrants (that is, the "brain drain"), talented artists, or entrepreneurs are examples of the effects of migration on the community of origin. Many studies have dealt with the demographic and economic effects of immigration on the community of destination (Smith and Edmonston 1997 exemplifies this type of study). And some research, such as the study of remittances, deals with the joint migration effects on origin and destination communities.

Most empirical migration studies deal with one or more of these four central questions. For example, the study of the effect of migration on the labour market in a destination country would likely involve selectivity issues (the first central question) and the effects of migration on unemployment levels and wage rates on the destination country (the fourth central question). The six papers in this special issue primarily deal with the progress of migrants after arrival (in Canada, France, and Britain), although they also discuss implications of the effects of migration.

\section{Lifecourse perspective}

The lifecourse perspective is inherently multidisciplinary and encompasses disciplines that include sociology, demography, psychology, and economics. Although empirical research from a lifecourse perspective has not developed a formal theory, the lifecourse perspective is widespread in the social sciences. This perspective views a lifelong process, starting at birth and ending at death. Because it is a lifelong process, it is guided by the choices people make about the paths they have taken, are taking, and will take throughout their lives. It takes an active perspective that does not focus on a particular event or point in time. Rather, it assumes that people are influenced by earlier events and that future decisions are affected by current choices. It assumes the role of human agency: that people are active participants in forming their lives and that people respond to the influences of other human agencies. The lifecourse perspective is influenced by the historical context of varying social, political, and economic conditions, creating distinctive influences for different age groups and a constantly changing environment in which individual life courses develop within available options.

The lifecourse perspective can be characterized by trajectories, transitions, turning points, and timing. Each of these four, alone or in combination, are seen in lifecourse studies.

- Trajectories are lengthy patterns of change and stability. For example, study of an individual's career involves examining their occupational and employment history, which may include a long time in the same occupation or periods of rapid occupational mobility.

- Transitions are life events that may cause changes in an individual's life and relationships. Change of employment is an example of a transition. 
Introduction by Edmonston (guest editor): Lifecourse perspectives on immigration

- Turning points are major transitions that cause a sharp change in the trajectory of an individual's life course. Retirement is one example of a turning point that greatly affects an individual's life course.

- Timing refers to the historical context or characteristics in a particular period (for example, World War II or a period of economic crisis). Timing can also apply to specific events taking place at certain ages (such as graduating high school at age 18 or getting married at age 32 ).

The lifecourse perspective can be used to make connections between events and their outcomes with regard to social behaviour-whether normal or abnormal behaviour-and how these affect an individual's later life. This perspective can be used, for instance, to understand the conditions associated with teenage pregnancy and its consequences in later life for marriage, educational achievement, and labour force participation.

The lifecourse perspective is useful for understanding the contexts under which people develop throughout their lives. The lifecourse approach looks to the aspect of continuity and change that life is inevitably characterized by, and looks to long-term consequences. It has been used to examine health, retirement, work, caregiving, and other social and economic aspects of life that cannot be readily understood without considering the underlying long-term influences. The lifecourse perspective looks at how age, life transitions, and the social context shape individual transitions throughout life.

A lifecourse perspective includes the study of the sequence of socially defined events and roles that the individual performs over time. This does not mean individual lives proceed or should proceed in a specific sequence. Rather, understanding a person's life requires looking at their event history, and significant events, experiences, or transitions that have taken place through a person's life from birth to death. For example, the lifecourse approach is often used when discussing the transition to retirement. To study this transition, the lifecourse perspective requires thinking about the lifelong process leading up to retirement. What were the decisions and choices about the paths that the individual took (or did not take) as an active participant prior to retirement? What was the influence of the changing social and economic conditions over their lifetime? What was the role of other human agents?

Glen Elder (1994 and 1998), one of the pioneers of the lifecourse perspective, has identified four themes in the lifecourse perspective: the interplay between individual lives and historical time, the timing of individual lives, linked lives, and human agency. It is useful to elaborate on each of these four themes and consider how they relate to specific topics for an immigrant's life course.

1. Lives and historical time: Time is a concept that is central to the lifecourse perspective. One component of time, historical time, creates varying contexts in which different birth cohorts negotiate their life courses.

The characteristics of immigrants are affected by selection factors that occur in the communities of origin and destination. Both origin country laws and selection laws in the country of destination influence who moves, and shape the particular ages and characteristics of immigrant cohorts. For example, countries usually have fairly specific laws regarding the migration of adoptees. Some origin countries do not allow the emigration of adoptees, or change their laws over time. Destination countries likewise have laws governing child migration and adoption. As a result, adoptees usually arrive from only a few origin countries, and immigrant adoptee cohorts reflect the changing laws in origin and destination countries as well as the changes in preferences of adoptee parents over time.

To provide another example, attitudes about immigration and immigrants have changed over time. Public opinion towards Chinese, Japanese, South Asian, and other Asian immigrants in North America has improved dramatically from the largely negative attitudes in the early 1900s to the more positive attitudes today. As a result, conditions for the integration and successful achievements of Asian immigrants in North America have become more favourable over time.

2. Timing of lives: Time also applies to expectations about when certain events or transitions should occur (timing) that serve as benchmarks for assessing transitions in terms of appropriate times or ages. For example, most societies have expectations about when to move out of a childhood home or when to have children. Some experience these events earlier or later than others, and some develop more complicated paths (for example, someone may have a teenage birth while living at home, leave home and have another birth, and then return home). Overall, the lifecourse approach directs attention towards the intricate connection between individual lives and the historical and socioeconomic context in which these lives unfold.

Migrants are greatly influenced by the timing of migration. Two demographic aspects particularly reflect the timing of migration: the immigrant's age and duration of residence in the destination community. Immigrants, by themselves or with a family, are more likely to move when they are younger adults. In many countries, including Canada, the age of immigrants is an important criterion of immigration selection and, as a matter of immigration policy, 
immigrants are likely to be younger adults. After arrival, duration of residence in the new country of settlement, together with age at arrival, have a critical influence for the adaptation of immigrants in the destination community.

The timing of lives affects comparisons between immigrants from different countries. Immigrants who arrive as refugees, for example, usually move during a limited period of time. Their ages at arrival and their duration of residence will generally differ from non-refugee immigrant groups who arrived earlier or later, and over longer periods of time.

3. Linked lives is a concept that emphasizes the interdependence of individual lives with others and the reciprocal influences of connected lives. This is a useful insight when applying the lifecourse perspective to family ties and aging. When considered in a multi-level model, there is also the potential for connecting interpersonal experiences in families with larger macro-level processes — such as the social, economic, and political forces of a particular historical time.

The lifecourse notion of linked lives (that is, that individuals are linked to family, workplace, and social networks over their lifetime) has a special place in migration analysis because migrants are "linked" closely to friends and families during the migration process. With rare exceptions, most migrants require help from their families and friends in order to facilitate international migration. Many immigrants require a family member or employer to sponsor them for immigration. For elderly immigrants, destination countries may require a financial contract or guarantee that the family will care for and provide financial support for the immigrant.

4. The lifecourse perspective's notion of buman agency is that individuals develop their lives in the context of many social and economic agencies. Childhood development is influenced by friends and families, schools, churches, and many other key social agencies. One critical aspect of lifecourse studies is to identify and understand the role and influence of human agency.

Migration is intrinsically motivated by and involves human agents. Immigrants decide whether to migrate and where to move, a decision-making process that usually involves other people. Human agencies include immigration programs and policies in the destination country that determine criteria such as age, sex, education and language qualifications, and other skills required for immigrant admission. In addition, other programs and policies in both the origin and destination countries affect migration.

\section{Lifecourse aspects of migration}

Although many topics of study for the general population might be examined in terms of migration, there are topics of special concern for immigration. Table 1 displays a cross-classification for six life cycle stages-children, youth, young adult, middle adult, older adult, and elderly—and eight social institutions_political/immigration, religious, family, employment/occupation, school/language, income, housing/mobility, and health. These categories are presented for illustrative purposes only and are not meant to be an exhaustive classification.

The cross-classification lists topics of particular interest for migration analysis. These are topics that are usually neglected in life course analyses for the general population. They are neglected mainly because they are not pertinent (for example, individuals who are citizens at birth are not concerned about seeking citizenship) or seldom occur (although emigration of Canadian citizens at birth does occur in Canada, most emigrants are persons who previously immigrated to Canada and subsequently decide to return to their country of origin or move to a third country).

This cross-classification highlights topics that warrant further attention from a lifecourse perspective, including:

- Political/Immigration: Because immigrants arrive in a new country of residence, political incorporation is an important topic for study. Not all immigrants remain in their new country, so studies of emigration or return migration are useful. For immigrants who remain, the initial critical step is gaining citizenship, which opens the path for voting and other acts of political activity, such as participation in a political party or running for election, and expanded job opportunities because some jobs may be limited to citizens.

- Religious: Immigrants often have different religious beliefs and affiliations than non-immigrants. Religious practices and beliefs, and interaction with others with different religious beliefs, are important topics for immigrant study. Also, some immigrants do not retain their original religious practices, and may convert to another religion, another topic that has not received much empirical study. Other immigrants retain their original religious affiliation, but may alter their practices (attending services more or less often) or change their religious beliefs (becoming more liberal or more conservative in their religious thinking).

- Family: The study of the immigrant family and related processes is essential for improving our understanding of immigrant adaptation. The immigrant family is chiefly responsible for socialization of their Canadian-born sons and 


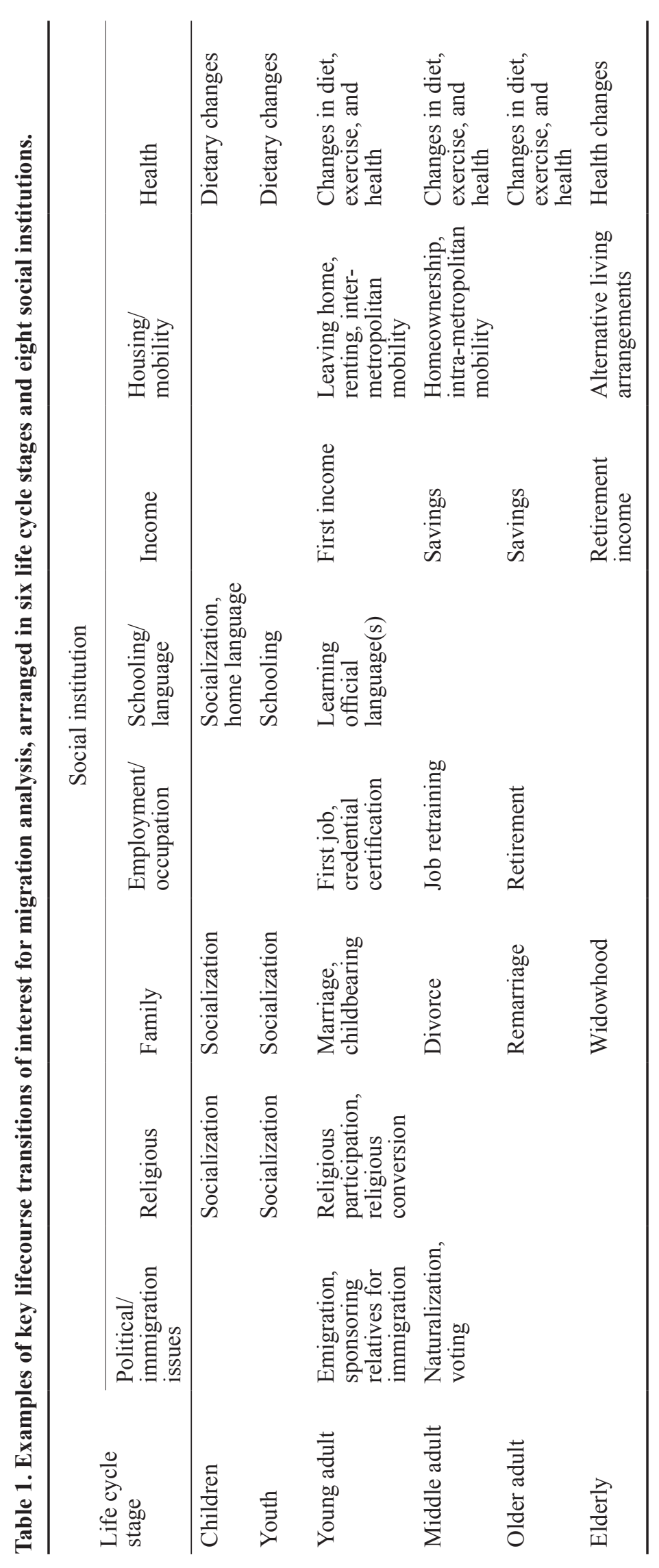


daughters, who become the second immigrant generation. Intergenerational exchanges are therefore a critical aspect for the study of successful immigrant adaptation. Additional topics for study include marriage (are immigrants more likely to marry within their ethnic, language, and religious group?), childbearing (do immigrants have more or fewer children?), divorce, remarriage, and widowhood (do immigrants have rates similar to others?).

- Employment/Occupation: Acquiring a first job and having a successful employment career are critical questions for immigration analysis because Canada's points-based immigration policy is closely-related to issues of labour market demands, immigrant skills, and employment. Key topics related to employment deal with the likelihood of employment, duration of unemployment, and the match between desired occupation and actual occupation.

- Schooling/Language: Immigrant families often have a home language that is neither English nor French. Non-official home languages provide a second (or third) language for immigrant children, although they may have special needs in learning an official language if they have limited English or French in their home. Children of immigrants need to acquire education in Canada in order to find suitable employment, and this is an essential topic for study.

- Income: Many empirical studies have focussed on wage and salary income, self-employment income, and family income in order to measure the economic success of immigrants and possible earnings gaps between immigrants and others. This is a significant area for research because the economic adaptation of immigrants, as indicated by earnings and income, is necessary for most other aspects of integration, including homeownership.

- Housing/Mobility: Households appreciate homeownership for its investment value, security, and privacy. The study of homeownership, therefore, is a key measure of how immigrants are doing as well as their attachment to a local area. Immigrants do not necessarily remain where they first settle in Canada. Some immigrants move to another province or another metropolitan area, while others stay within the metropolitan area but move locally. Whether immigrants move in the same way as others is an interesting topic for study, because immigrants reshape both the areas they leave as well as the new destination areas.

- Healtb: There are several interesting relationships between migration and health that warrant the attention of researchers and policymakers. Although some immigrants—especially refugees—may arrive in poor health, most immigrants are noteworthy for being in relatively good health (in many destination countries, immigration policy is designed to restrict the entrance of migrants with serious illness or poor health). This healtby immigrant selection effect has been studied primarily because the foreign-born population usually has lower mortality than the rest of the resident population. On the other hand, researchers have noticed that the health of migrants becomes more similar to the average person in their new destination over time. This assimilation to the average is generally understood to occur as migrants adopt the lifestyle and dietary habits of the average person in their new community over time.

\section{Data and methods}

Quantitative life course analysis has benefitted greatly by the recent expansion of suitable data sources and the development of appropriate statistical methods. Most life course analysis is based on special types of census or survey data. Four types of data are the main sources for statistical analysis (Edmonston 1996 provides more detailed discussion of various types of data suitable for longitudinal analysis). The six papers presented in this issue rely on several of these four data types, and illustrate their advantages and limitations.

The first type is new prospective data, defined as data in which a group of respondents are surveyed and then followed over time with regular surveys. In some cases, the prospective data include information from administrative sources, such as employment or tax records. These are expensive to collect and take a long time to accumulate data for analysis. This approach has the advantage, however, of being able to collect contemporary data from respondents as conditions change and events occur.

The second data type is retrospective data, which is obtained when a survey asks respondents about events and conditions in the past. This type of data is less expensive than a prospective survey and provides immediate data for analysis. It is a useful data source for understanding the duration between major events, such as the time between marriage and the first birth of a child. The disadvantage of retrospective data is that information is affected by unknown selection (not all immigrants, for example, may still be alive or still residing in their destination country) and recall (respondents do not always remember key events or are able to recall their dates) biases.

Life course information can be collected in a third way: by linking current census or survey data with past administrative records. Most data of this type involve linking current survey data with prior immigration, income, or 
Introduction by Edmonston (guest editor): Lifecourse perspectives on immigration

employment records. This is an inexpensive approach for collecting information on changes over time. But the data are limited to the content of administrative records.

A fourth data type is based on synthetic cohorts in censuses and surveys. This approach relies on birth or immigration cohorts for analysis, rather than on individuals. Studies usually follow an immigrant cohort (a group of immigrants arriving during the same period, such as the 1980s) through time, using several censuses or surveys in order to understand changes such as labour force participation or hourly wages, compared to other residents. It has the advantage of providing inexpensive data for longer periods of time. But analysis is limited to cohort comparisons, with potential selection biases.

Current life course analysis relies on several multivariate statistical tools. Statisticians proposed new methods for the analysis of event changes several decades ago, which have evolved to the current generalized linear mixed models (also known as multilevel or hierarchical models) that are suitable for the analysis of continuous, binary, or count data over time. The generalized linear mixed models have been implemented in several statistical packages and are described in applied statistics textbooks (see Singer and Willett 2003; Rabe-Hesketh and Skrondal 2012). Other statistical methods, such as the double-cohort approach (Myers and Lee 1996) that is used in the Edmonston and Lee paper in this special issue, have been developed in recent years for purposes of immigration analysis.

\section{Papers in this special issue}

This volume includes six papers that illustrate new ways of using a lifecourse perspective for migration analysis.

Saïd Ahmed Aboubacar and Nong Zhu analyze longitudinal survey data from Statistics Canada's Survey of Labour and Income Dynamics, a household survey that provides information on fluctuations in income and employment over time. Aboubacar and Zhu analyze the occurrence of non-employment for immigrants from developing countries and their situation compared to immigrants from developed countries and those born in Canada. Their study concludes that there are important differences between the three groups in the stability of employment, hours spent in episodes of non-employment, and factors that influence the propensity to depart episodes of non-employment. These differences demonstrate several disadvantages for immigrants from developing countries in their Canadian employment histories.

Eric Fong and Peter Shi Jiao analyze survey data collected in Toronto to study job mismatch among Chinese and Asian Indian immigrants. Using data on employment prior to immigration and employment after arrival in Canada, they conclude that a high proportion of immigrants do not find employment in the same occupation and industry. Contrary to previous studies, they find that the relationship between education and job match before and after immigration requires additional careful definition. Their analysis shows that place of education matters for the first job of those who have not changed their job since immigration. They find that foreign education, however, is not related to the first job of immigrants who later changed their job. Their sample size is too small to analyze job mismatch separately for males and females, which is an important topic for future studies.

Jacques Ledent, Cheryl Aman, Bruce Garnett, Jake Murdoch, David Walters, and Marie McAndrew use provincial and metropolitan data to analyze academic performance and educational pathways for immigrant youth in Montreal, Toronto, and Vancouver. Their data include most — if not all (in Montreal) — high school students in the three metropolitan areas that were expected to graduate in 2004. Their analysis suggests the usefulness of including many of the variables found in provincial and local databases as explanatory variables in multivariate analysis. The authors emphasize one important caution in interpreting their results: there are too many differences between Montreal, Toronto, and Vancouver school systems to make definitive comparative statements about academic performance in the three metropolitan areas.

Sharon Lee and Barry Edmonston use a lifecourse perspective and a double-cohort model to analyze 1991, 1996, 2001, and 2006 census data to study homeownership attainment among immigrants. The double-cohort model is useful for separating aging and duration of residence processes by embedding immigrant cohorts within a series of birth cohorts. They ask whether immigrants are less likely to be homeowners than the Canadian-born, and whether recent immigrants are less likely to own homes than earlier immigrant cohorts. While descriptive findings suggest that immigrants, particularly recent arrivals, have lower homeownership rates than the Canadian-born, multivariate results qualify this impression. The double-cohort model with additional variables shows that immigrants' transition to homeownership does not greatly differ from the Canadian-born. Recent arrivals begin with lower levels of homeownership but they rapidly close the gap in homeownership over their life course.

Jean-Luc Richard describes the value of analyzing France's Permanent Demographic Sample for migration analysis. This dataset is a census-based panel study that includes 1 per cent of all French immigrants. The dataset was 
originally created in 1967 and has been linked to data from the 1968, 1975, 1982, 1990, and 1999 censuses-suggesting a model for longitudinal datasets for other countries with regular censuses. Richard's empirical analysis makes clear that it is not easy for young immigrants in France to find suitable employment. Gaining French citizenship helps, but immigrants living in segregated urban areas find it difficult to gain employment. His research acknowledges that France has to face difficult policy options in order to improve the current situation for younger immigrants.

JuYin Helen Wong's paper deals with the time to first employment for immigrants in Great Britain. Most previous studies have analyzed either cross-sectional or several surveys or censuses over time. By analyzing retrospective longitudinal data, collected by the Family and Working Lives Survey in 1994-1995, this PhD student examines ethnic variations in the duration between arrival in Great Britain and first employment. The advantage of longitudinal data for this research is that the analysis can disentangle temporal, contextual, and individual changes over time. Wong's analysis suggests that several ethnic groups - including African, Caribbean, and Pakistani immigrants—-take longer to find first employment than other groups. This type of study, however, looks only at the beginning of individual employment careers. Additional studies are needed to look at occupational transition after first employment, and whether immigrants acquire additional qualifications and improve their initial employment in later years.

\section{Concluding remarks}

The papers in this special issue provide a sampling of empirical research on migration and immigrants using the lifecourse perspective. Each adds to the current understanding of migration and immigrants by focusing on different aspects and stages of immigrants' life courses, and identifies questions for further study. Together they demonstrate, as discussed earlier, both theoretical and empirical challenges for migration analysis. Overall, the papers show that analysis from a lifecourse perspective illuminates immigration in new ways, and provides insightful and useful ideas about determinants and adjustments involved in migration.

\section{References}

Edmonston, B. 1996. Statistics on US Immigration: An Assessment of Data Needs for Future Research. Washington, DC: National Academy Press.

Elder, G.H. 1994. Time, human agency, and social change: Perspectives on the life course. Social Psychology Quarterly 57:571-590.

— 1998. The life course as development theory. Child Development 69(February):1-12.

Glick, P.C. 1988. Fifty years of family demography: A record of social change. Journal of Marriage and the Family 50(November):861-873.

Jasso, G. 2003. Migration, human development, and the life course, in Handbook of the Life Course, edited by J.T. Mortimer and M.J. Shanahan. New York: Kluwer Academic/Plenum Publishers.

Myers, D., and S.W. Lee. 1995. Immigration cohorts and residential overcrowding in Southern California. Demography 33(February):51-65.

Rabe-Hesketh, S., and A. Skrondal. 2012. Multilevel and Longitudinal Modeling Using Stata. 3rd edn. College Station, TX: Stata Press.

Singer, J.D., and J.B. Willett. 2003. Applied Longitudinal Data Analysis: Modeling Change and Event Occurrence. Oxford: Oxford University Press.

Smith, J.P., and B. Edmonston. 1997. The New Americans: Economic, Demographic, and Fiscal Effects of Immigration. Report of the National Academy of Sciences. Washington, DC: National Academy Press.

Thomas, W.I., and F.W. Znaniecki. 1958. The Polish Peasant in Europe and America. 2 vols, repr. edn. New York: Dover. (original edn. 1918-1920) 